\title{
КОНЦЕПТУАЛЬНЫЕ ОСНОВЫ РАЗРАБОТКИ МОДЕЛИ КОМПЕТЕНЦИЙ В ДЕЯТЕЛЬНОСТИ МЕНЕДЖЕРА ПО ПЕРСОНАЛУ
}

Рассматриваются проблемы и перспективы внедрения компетентностного подхода в деятельности менеджсра по персоналу. В развитии модели компетенций менеджсров видится перспектива получения количественного и качественного эффекта на региональном и федеральном уровнях. Анализируется опьгт фирм, успешно действующих в России и ориентированных на повьиение компетентности своего персонала.

Рассмотрены проблемы внедрения модели компетенций из-за недостаточно чёткого определения понятия компетенци. Выявлены основные модели и рассмотрен поэтапный алгоритм их внедрения. Определены проблемы внедрения компетентностного подхода и проведен анализ благоприятных предпосылок для развития компетентностного подхода в деятельности менеджера по персоналу.

Ключевые слова: компетенции менеджера, профессионализм, разработка и эффект модели компетенций.

\section{Dina Chuprova, Svetlana Fedorova \\ CONCEPTUAL BASES OF A COMPETENCIES MODELS DEVELOPMENT IN THE HUMAN RESOURCES MANAGER ACTIVITIES}

The problems and prospects of the competence approach implementation in the activities of an HR manager are discussed. In the development of the competency model of managers the prospect of obtaining quantitative and qualitative effect on regional and Federal levels is noted. The experience of the companies successfully operating in Russia and aimed at enhancing the competence of its staff has been analyzed.

The problems of the implementation of the competence model due to the insufficiently clear definition of the concept of competence are considered. The main models are identified and a phased algorithm for their implementation is considered. The problems of the implementation of the competence approach are identified and the analysis of the favorable prerequisites for the development of a competence approach in the activity of the personnel manager is carried out

Key words: the competence of an HR manager, the professionalism, development and effect of a competency model.

Bведение / Introduction. Современный менеджмент предполагает постоянное повышение качества управленческой деятельности, что становится возможным только при осуществлении кадровой политики, нацеленной на улучшение результатов.

Целью данной статьи является создание матрицы компетенций с учетом специфики организации и на основе профессионального стандарта специалиста по управлению персоналом.

Создание модели, в которой будут представлены компетенции для hr-менеджера, поможет повысить эффективность специалистов, поставить четкие цели и отследить результаты. Современные специалисты по кадрам ищут новые пути работы с персоналом, к которым можно отнести применение теории поколений, геймификацию, тренинги и командообразование [4].

Утвержденный в 2015 г. профессиональный стандарт помогает создавать модель компетенций с учетом поведенческих, профессиональных навыков, знаний и способностей, необходимых сотруднику не только для успешного выполнения текущих рабочих функций, но и для саморазвития во внерабочее время. Данный документ предполагает не только выполнение профессиональных обязанностей, но и следование нормам этики и делового общения, что требует знаний в области менеджмента, экономики, психологии и социологии. 
Использование компетентностного подхода, наряду с современными методами управления, используемыми при подборе специалистов по персоналу, способствует наилучшему выбору, позволяя сохранить время и сократить издержки на персонал [6].

Общее мнение о личностных и профессиональных качествах, необходимых менеджеру по персоналу, до сих пор не сформировано.

Maтериалы и методы / Materials and methods. Развитию работников и формированию профессиональных компетенций работников уделяется большое внимание. Опыт организаций, присутствующих на мировом рынке, показывает, что преимущество бывает у тех фирм, где заняты наиболее квалифицированные кадры. Это исторически объясняется тем, что накопленный профессионализм помогает гибко реагировать на изменения внешней среды, быстро приобретать навыки и обучать других. Возникло целое направление по изучению компетенций и их определений. В то же время следует отметить, что проблема компетентности служащих не является принципиально новой.

Современная модель компетенций работника предполагает определять функционал специалиста; учитывать широту его профессионального профиля; опираться на профессиографические характеристики и оценки экспертов на ближайшую и отдаленную перспективу [2]

Мы предлагаем рассматривать модель специалиста по персоналу в совокупности следующих компонентов: набор профессионально-должностных умений, сочетающих в себе необходимые виды профессиональной деятельности и наличие определенных психологических установок и норм личности.

Укрупненно модель компетенций состоит из трех основных блоков, показанных на рисунке 1

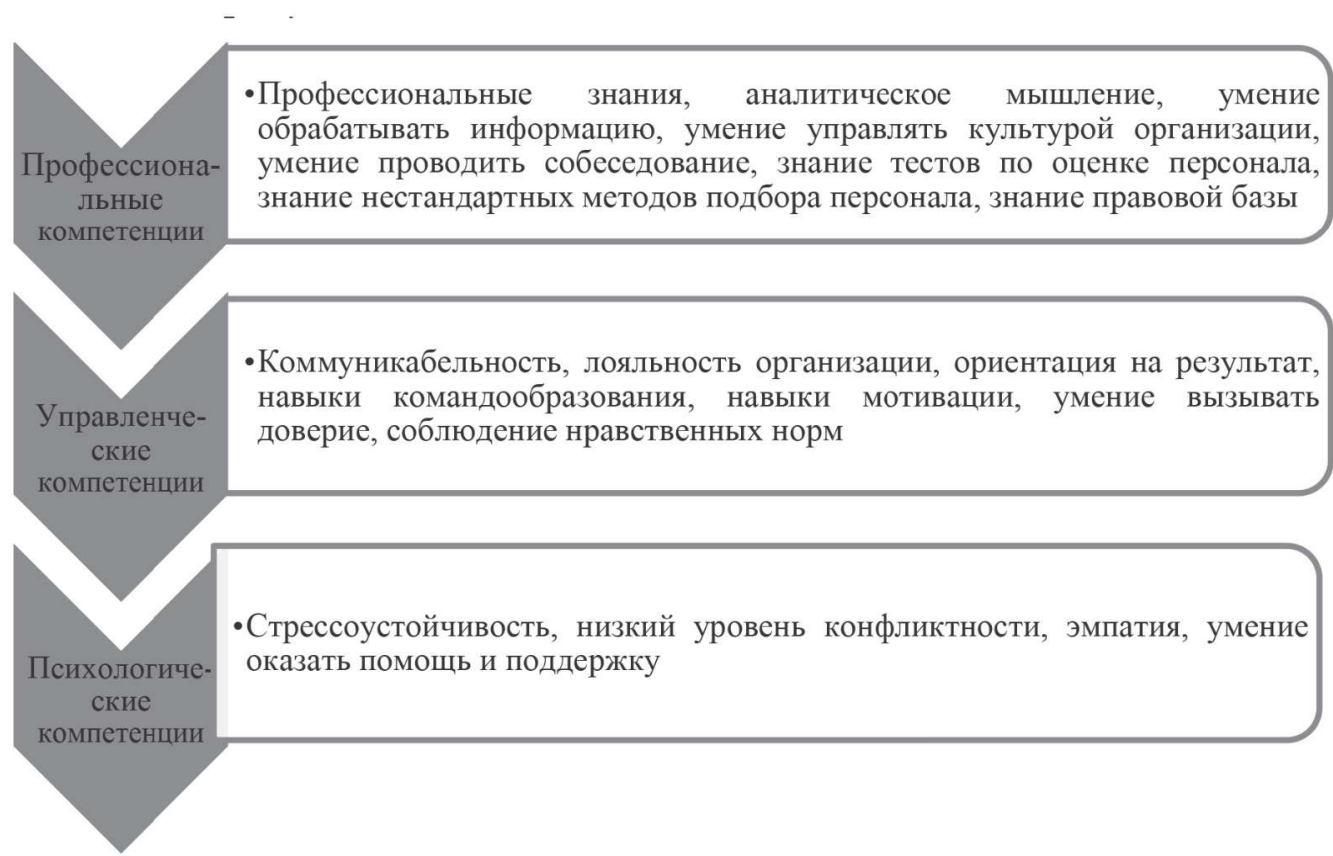

Рис. 1. Основные блоки модели компетенций специалиста по персоналу

Профессиональный опыт, приобретенный ранее, оказывает большое влияние на компетентность специалиста и позволяет в зависимости от ранее приобретенных знаний и навыков расширять функционал специалиста. Совокупность профессиональных умений и навыков содержит также элемент творчества. Развитие умений и навыков определяет качество деятельности специалиста, расширяет профессиональный опыт, формирует личностные качества. 
По нашему мнению, при оценке компетенций следует использовать шкалу, помогающую оценить важность наличия компетенции у специалиста с учетом сферы деятельности организации.

Так, например, в бюрократических организациях умение управлять культурой организации, знание нестандартных методов подбора персонала и коммуникабельность не являются главенствующими компетенциями. В то время как в клановой культуре основными компетенциями специалиста по кадрам будут лояльность организации, умение оказать помощь и поддержку, эмпатия.

Результаты и обсуждение / Results and discussion. Проведенное исследование деятельности менеджеров по персоналу показывает, что разработка компетентностной модели менеджера по персоналу требует знаний отраслевой принадлежности, для которой создается профиль компетенций специалиста. При этом целесообразно разделять компетенции на профессиональные, управленческие и психологические.

Кроме того, обязательным условием для реализации модели компетенций является систематическое изменение оцениваемых компетенций с учетом быстро изменяющихся факторов внешней среды.

Разработка моделей компетенций предполагает определённый алгоритм последовательных действий, состоящий из трех этапов, представленных на рисунке 2.



Рис. 2. Этапы создания модели компетенщий

На первом этапе формулируется желаемый результат от предстоящей деятельности, определяются сроки реализации проекта.

Второй этап направлен на создание команды проекта. Здесь определяются наиболее авторитетные сотрудники подразделений, способных к продуктивной деятельности.

Успех заключительного этапа напрямую зависит от количества и качества собранной информации о деятельности, реализующейся в данной организации, об участниках этой деятельности, об организационной культуре, способствующей эффективному достижению цели деятельности организации.

Заключение / Conclusion. Процесс создания модели компетенций является комплексным, направленным на повышение профессионализма на основе приобретения профессиональных знаний, опыта и необходимых способностей [1]. 
Для того чтобы модель стала действенным инструментом, требуется определить условия, определяющие ее функционирование.

В ходе исследования нами были выделены следующие условия реализации модели компетенций:

- создание модели компетенций с учетом специфики деятельности организации;

- систематический пересмотр и корректировка требуемых и существующих компетенций;

- информирование персонала о ходе разработки модели компетенций;

- внедрение модели компетенций в практику менеджмента.

Разработка модели компетенций является трудоемким процессом и требует определенного мастерства от специалиста, разрабатывающего модель.

Учитывая, что оценка эффективности предлагаемых мероприятий по внедрению модели компетенций в организации требует определенных инвестиций, на плановом этапе определяются издержки, с которыми придется столкнуться в процессе реализации данного проекта.

Таким образом, анализ деятельности организаций, внедряющих в свою деятельность модель компетенций, показал, что созданная модель позволяет сокращать численность низкоквалифицированных кадров, не сокращая объема выполненной работы, что означает повышение производительности труда служащих.

Подводя итог, необходимо отметить, что новый подход к оценке персонала должен иметь единую направленность и обеспечивать высокую экономическую и социальную эффективность деятельности организации.

\section{ЛИТЕРАТУРА И ИНТЕРНЕТ-РЕСУРСЫ}

1. Компетентностный подход. Реферативный бюллетень РГГУ. 2005 г. [Электронный ресурc]. URL: http://www.rsuh.ru/binary/56572_11.1173464019.22977.doc

2. Кризис компетентностного подхода в управлении персоналом [Электронный реcypc]. URL: http:// www.naim.ru/nodes/

3. Мелихов Ю. Е., Малуев П. А. Управление персоналом. Портфель надежных технологий: учебно-практическое пособие. 2-е изд. М: Дашков и $\mathrm{K}^{\circ}, 2012.342$, [1] с.

4. Trainings $4 \mathrm{Jobs}^{\mathrm{TM}}$ - инновации в развитии компетенций на рабочем месте [Электронный ресурс]. URL: http://www.cnt-consult.ru/russia/blog/SKBlog/181.php

5. Competencies and competency models: Does one size fit all? / Patricia K. Zingheim, Ph. D., Gerald L. Ledford Jr., Ph. D., and Jay R. Schuster, Ph. D. // ACA Journal. Spring 1996. Volume 5. No. 1. Pp. 56-65.

6. The practice of competency modeling / Jeffery S. Shippmann, Ronalda A. Ash, Mariangela Batjista, Linda Carr, Lorrained D. Eyde, Beryl Hesketh, Jerry. Kenoe, Kenneth Pearlman, Erich P. Prien, Juan I. Sanches // Personnel psychology. Volume 53. Issue 3. September 2000 . Pp. 703-740.

\section{REFERENCES AND INTERNET RESOURCES}

1. Kompetentnostnyi podkhod. Referativnyi byulleten' RGGU. 2005 g. URL: http://www.rsuh.ru/bina ry/56572_11.1173464019.22977.doc

2. Krizis kompetentnostnogo podkhoda $\mathrm{v}$ upravlenii personalom. URL: http://www.naim.ru/nodes/

3. Melikhov, Yu. E., Maluev P. A. Upravlenie personalom. Portfel' nadezhnykh tekhnologii (Personnel management. Portfolio of reliable technologies): uchebno-prakticheskoe posobie. 2-e izd. M.: Dashkov i $\mathrm{K}^{\circ}$, 2012. 342[1] C.

4. Trainings4Jobs ${ }^{\mathrm{TM}}$ - innovatsii v razvitii kompetentsii na rabochem meste. URL: http://www.cnt-consult.ru/ russia/blog/SKBlog/181.php

5. Competencies and competency models: Does one size fit all? / Patricia K. Zingheim, Ph. D., Gerald L. Ledford Jr., Ph. D., and Jay R. Schuster, Ph. D. // ACA Journal. Spring 1996. Volume 5. No. 1. Pp. 56-65.

6. The practice of competency modeling. Jeffery S. Shippmann, Ronalda A. Ash, Mariangela Batjista, Linda Carr, Lorrained D. Eyde, Beryl Hesketh, Jerry. Kenoe, Kenneth Pearlman, Erich P. Prien, Juan I. Sanches // Personnel psychology. Volume 53. Issue 3. September 2000 . Pp. 703-740. 


\section{СВЕДЕНИЯ ОБ АВТОРАХ}

Чупрова Дина Борисовна, кандидат экономических наук, доцент, кафедра государственного и муниципального управления, Институт экономики и управления, Северо-Кавказский федеральный университет. E-mail: Dina.chyprova@mail.ru

Федорова Светлана Алексеевна, кандидат педагогических наук, доцент, кафедра государственного и муниципального управления, Институт экономики и управления, Северо-Кавказский федеральный университет. E-mail: kul14@yandex.ru

\section{INFORMATION ABOUT AUTHORS}

Dina Chuprova, Associate Professor, Cand.Sci (Economics), Department of State Municipal Management. North Caucasus Federal University, Stavropol, Russia. E-mail: Dina.chyprova@mail.ru

Svetlana Fedorova, Associate Professor, Candidate of pedagogical Sciences, Department of State Municipal Management. North-Caucasus Federal University. Stavropol, Russia. E-mail: kul14@yandex.ru 